\section{THU0183 LESS PAIN OVER 2 YEARS WITH BIOLOGICAL COMPARED TO CONVENTIONAL COMBINATION THERAPY IN EARLY RHEUMATOID ARTHRITIS: RESULTS FROM THE RANDOMISED CONTROLLED SWEFOT TRIAL}

T. Olofsson ${ }^{1}$, J.K. Wallman ${ }^{1}$, A. Jöud ${ }^{2}$, M.E. Schelin ${ }^{3}$, S. Ernestam ${ }^{4,5}$, R. van Vollenhoven ${ }^{5}$, S. Saevarsdottir ${ }^{5}$, J. Lampa $^{5}{ }^{1}{ }^{1}$ Rheumatology, Department of Clinical Sciences Lund; ${ }^{2}$ Occupational and Environmental Medicine; ${ }^{3}$ Oncology, Department of Clinical Sciences Lund, Lund University, Lund; ${ }^{4}$ Academic Specialist Centre, Stockholm Health Services; ${ }^{5}$ Rheumatology Unit, Department of Medicine, Karolinska Institute, Stockholm, Sweden

Background: Pain is a common and debilitating feature of rheumatoid arthritis (RA) and a level $>40 \mathrm{~mm}$ on a Visual Analogue Scale (VAS) of pain (scale 0$100 \mathrm{~mm}$ ) has been suggested as a measure of unacceptable pain. ${ }^{1}$ While many studies have focused on the effect on inflammation of different pharmacological options, few earlier reports have directly compared pain outcomes between common treatment strategies.

Objectives: The aim of this study was to investigate pain development and unacceptable pain over 2 years after start of biological as compared to conventional combination therapy in early RA patients.

Methods: The multicentre SWEFOT (SWedish FarmacOTherapy) trial was designed as a randomised, active-controlled, open-label study, enrolling newonset (<1 year) patients fulfilling 1987 American College of Rheumatology criteria for RA Oct 2002 to Dec 2005. After a 3 month run-in period on methotrexate (MTX), patients who did not reach low disease activity (Disease Activity Score using 28-joint count; DAS28 $\leq 3.2$ ) were randomised to addition of infliximab (IFX) or sulfasalazine +hydroxychloroquine (SSZ +HCQ). Results for disease activity, radiographic data and health-related quality-of-life have been published earlier. ${ }^{2,3}$ Here, unacceptable pain (VAS pain $>40 \mathrm{~mm}$ ) at 2 years follow-up and area under the curve (AUC) for VAS pain were used as outcome measures. We used intention-to-treat with last observation carried forward in case of protocol breach as study approach. Statistical analyses were performed by logistic regression for unacceptable pain and analysis of covariance for AUC for VAS pain, adjusting for age, sex, and VAS pain at randomisation.

Results: 487 RA patients were enrolled of whom 258 (who did not respond sufficiently to MTX) were randomly allocated to either addition of IFX ( $n=128)$ or SSZ $+\mathrm{HCQ}(n=130)$. Baseline characteristics were similar between the two groups. Out of patients assigned to IFX, 32\% had unacceptable pain at 2 years follow-up (21 months after randomisation), while the same figure for SSZ+HCQ $(n=130)$ was $45 \%$ (adjusted odds ratio 0.41 [95\% $\mathrm{Cl} 0.23-0.73]$; $p=0.003$ ). Serial VAS pain measurements are displayed in figure 1. An AUC analysis for mean VAS pain levels from randomisation to 2 years follow-up confirmed significantly lower levels for patients randomised to IFX compared to SSZ+HCQ $(p=0.01)$.

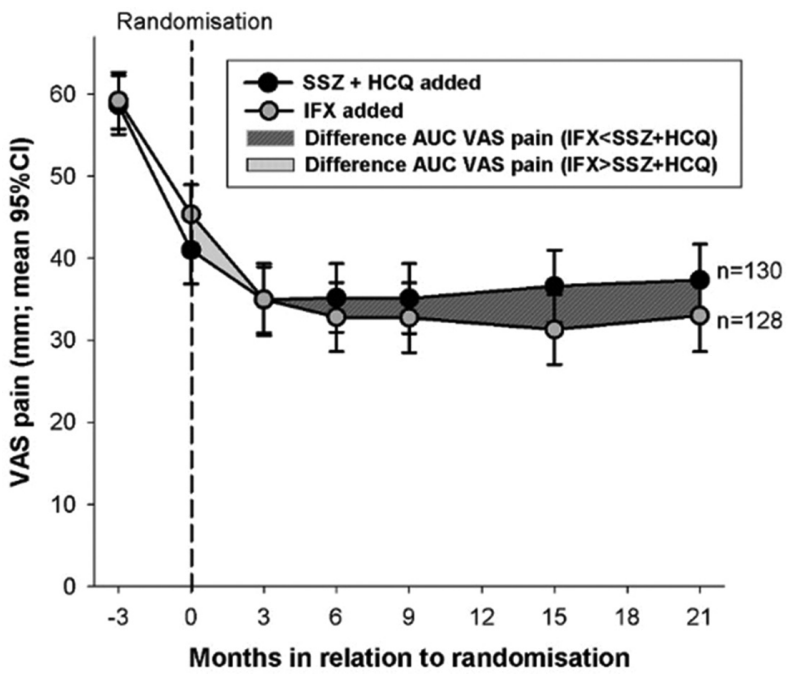

Conclusions: Despite early active treatment, a large share of new-onset RA patients showed unacceptable pain after 2 years. Interestingly, both the fraction of patients with unacceptable pain and assessment of pain over time were substantially lower for patients randomised to addition of IFX compared to SSZ+HCQ, contrasting to earlier SWEFOT reports where significant between-group differences at 2 years follow-up for disease activity and health-related quality-of-life were not seen. ${ }^{2,3}$ This suggests a better effect on long term pain for the biological therapy, which could be taken into account when choosing treatment strategy in patients responding insufficiently to MTX.

\section{REFERENCES:}

[1] Tubach, et al. Arthritis Care Res 2012;64:1699-70.

[2] van Vollenhoven, et al. Lancet 2012;379:1712-20.

[3] Karlsson, et al. Ann Rheum Dis 2013;72:1927-33.

Disclosure of Interest: T. Olofsson: None declared, J. Wallman Consultant for: AbbVie, Celgene, Eli Lilly, Novartis, UCB, A. Jöud: None declared, M. Schelin: None declared, S. Ernestam: None declared, R. van Vollenhoven Grant/research support from: AbbVie, BMS, GSK, Pfizer, UCB, Consultant for: AbbVie, AstraZeneca, Biotest, BMS, Celgene, GSK, Janssen, Lilly, Novartis, Pfizer, UCB, S. Saevarsdottir: None declared, J. Lampa Grant/research support from: AbbVie, Speakers bureau: AbbVie, Eli Lilly, Hospira, MSD, Novartis, Pfizer, Roche, Sandoz, UCB

DOI: 10.1136/annrheumdis-2018-eular.1844

\section{THU0184 IMPACT OF IMMUNOGENICITY ON CLINICAL EFFICACY AND ADMINISTRATION RELATED REACTION IN TNF INHIBITORS: A POOLED-ANALYSIS FROM THREE BIOSIMILAR STUDIES IN PATIENTS WITH RHEUMATOID ARTHRITIS}

P. Emery ${ }^{1}$, M. Weinblatt ${ }^{2}$, J.S. Smolen ${ }^{3}$, E. Keystone ${ }^{4}$, M. Genovese ${ }^{5}$ J. Vencovsky ${ }^{6}$, J. Kay ${ }^{7}$, E. Hong ${ }^{8}$, Y. Baek ${ }^{8}$, J. Ghil ${ }^{8} .{ }^{1}$ Leeds Institute of Rheumatic and Musculoskeletal Medicine, Leeds, UK; ${ }^{2}$ Brigham and Women's Hospital, Boston, USA; ${ }^{3}$ Medical University of Vienna, Vienna, Austria; ${ }^{4}$ Mount Sinal Hospital, Toronto, Canada; ${ }^{5}$ Stanford University Medical Center, Stanford, USA; ${ }^{6}$ Institute of Rheumatology, Prague, Czech Republic; ${ }^{7}$ University of Massachusetts Medical School, Worcester, USA; ${ }^{8}$ Samsung Bioepis Co., Ltd., Incheon, Korea, Republic of Ireland

Background: SB4, SB2, and SB5 are biosimilars of reference etanercept, infliximab, and adalimumab, respectively. The phase III randomised, double-blind clinical studies comparing the efficacy and safety of each biosimilar with its reference product had similar study designs, patient demographics, and the same primary endpoint of the ACR20 response rate. In each study immunogenicity was measured using a validated ECL assay tagged with the biosimilar.

Objectives: To assess the immunogenicity of three TNFi and examine the potential impact of anti-drug antibodies (ADAbs) on efficacy and injection site reactions (ISR) or infusion related reactions (IRR) by a pooled analysis of three biosimilar studies. ${ }^{1-3}$ Data to the time of the primary endpoint for each study (week 24 for etanercept and adalimumab studies and week 30 for infliximab study) are presented.

Methods: Data from patients who had immunogenicity results from each phase III study were pooled. Efficacy (ACR responses, clinical response [defined as good or moderate EULAR response], change in disease activity [DAS28, SDAI, $\mathrm{CDAI}$ ) and ISR/IRR were evaluated in relation to the presence of ADAb (at least one ADAb positive result up to when the primary endpoint was measured).

Results: The analysis included 1710 patients and the incidence of ADAb by treat ment group is presented in the table 1 .

Across treatment groups, efficacy was greater in patients without ADAb compared to those with ADAb. In all treatments combined, the ACR20 response rate was lower in the presence of ADAb (OR 2.06, 95\% Cl: 1.63-2.60, p<0.0001) (figure 1) and the mean improvement in DAS28 was significantly greater in patients without ADAb (estimated difference: $0.383,95 \% \mathrm{Cl}: 0.24-0.52, \mathrm{p}<0.0001$ ). The ADAb effect on reducing ACR20 response rates as well as other efficacy parameters was similarly observed in other treatment groups.

In all treatments combined, the presence of ADAb was associated with increased ISR/IRR (OR 1.73, 95\% Cl: 1.02-2.96, $\mathrm{p}=0.043$ ), predominantly with the infliximab combined (OR 2.67, 95\% Cl: 1.04-6.89, $p=0.041$ ) rather than the etanercept combined (OR 1.72, 95\% Cl: 0.38-7.77, $\mathrm{p}=0.478$ ) and adalimumab combined (OR 1.00, 95\% Cl: 0.35-2.88, p=0.998).

Abstract THU0184 - Table 1. Incidence of Anti-drug Antibody (n/n')

\begin{tabular}{lcccccc}
\hline Treatment & SB4 & ETN & SB2 & INF & SB5 & ADA \\
\hline ADAb & $2 / 299$ & $39 / 297$ & $158 / 287$ & $145 / 292$ & $88 / 266$ & $86 / 269$ \\
Incidence & $(0.7 \%)$ & $(13.1 \%)$ & $(55.1 \%)$ & $(49.7 \%)$ & $(33.1 \%)$ & $(32.0 \%)$ \\
Treatment & SB4 & SB2+INF & SB5 & Biosimilars & RP & All treatments \\
& +ETN & & +ADA & combined & combined & combined \\
ADAb & $41 / 596$ & $303 / 579$ & $174 / 535$ & $248 / 852$ & $270 / 858$ & $518 / 1710$ \\
Incidence & $(6.9 \%)$ & $(52.3 \%)$ & $(32.5 \%)$ & $(29.1 \%)$ & $(31.5 \%)$ & $(30.3 \%)$ \\
\hline
\end{tabular}

ADA, adalimumab reference product; ADAb, anti-drug antibody; ETN, etanercept reference product; INF, infliximab reference product; RP: reference product 


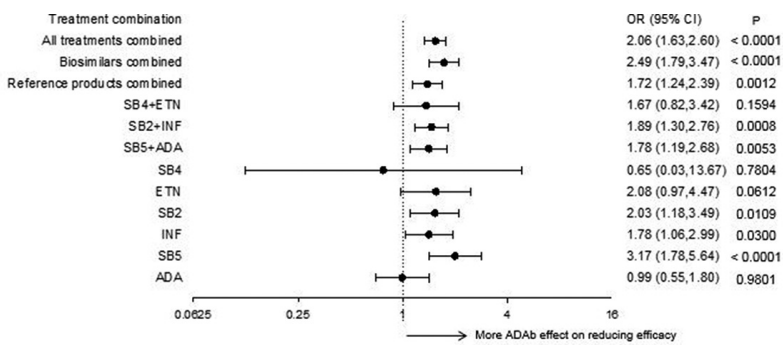

Abstract THU0184 - Figure 1. Effect of Anti-drug Antibody on ACR20 Response Rates

Conclusions: In a pooled analysis, the development of ADAbs to TNFi is associated with reduced clinical efficacy and increased incidence of ISR/IRR in patients with RA.

\section{REFERENCES:}

[1] Emery, et al. Ann Rheum Dis 2017 Jan;76(1):51-57.

[2] Choe, et al. Ann Rheum Dis 2017 Jan;76(1):58-64.

[3] Weinblatt, et al. Arthritis Rheumatol 2018 Jan;70(1):40-48.

Disclosure of Interest: P. Emery Consultant for: Pfizer, MSD, AbbVie, BristolMyers Squibb, UCB, Roche, Novartis, Samsung, Sandoz and Lilly, M. Weinblatt Grant/research support from: Amgen, Bristol-Myers Squibb, Crescendo Bioscience, Sanofi, Consultant for: AbbVie, Amgen, Novartis, Roche, GlaxoSmithKline, Merck, Samsung, Crescendo Bioscience, and AstraZeneca, and BristolMyers Squibb, Lilly, Pfizer, and UCB, J. Smolen Grant/research support from: AbbVie, Janssen, MSD, Pfizer, Roche and UCB, Consultant for: AbbVie, Amgen, AstraZeneca, Astro-Pharma, Celgene, GSK, Janssen, Lilly, Medimmune, MSD, Novartis-Sandoz, Novo Nordisk, Pfizer, Roche, Samsung Bioepis, Sanofi and UCB, E. Keystone Consultant for: Abbott, AstraZeneca, Bristol-Myers Squibb, Crescendo Bioscience, F. Hoffmann-La Roche, Genentech, Janssen, Lilly, Merck, Pfizer, UCB, Samsung Bioepis, M. Genovese Consultant for: Samsung, Merck, Abbvie, Amgen, BI, J. Vencovsky Consultant for: Samsung Bioepis, Biogen, J. Kay Consultant for: Alexion; Amgen; AbbVie; AstraZeneca; Boehringer Ingelheim; BMS; Crescendo Bioscience; Eli Lilly; Epirus; Genentech; GlaxoSmithKline; Hospira; Janssen; MSD; Novartis; Pfizer; Samsung Bioepis; Sandoz; Roche; UCB, E. Hong Employee of: Samsung Bioepis, Y. Baek Employee of: Samsung Bioepis, J. Ghil Employee of: Samsung Bioepis DOI: 10.1136/annrheumdis-2018-eular.4362

\section{THU0185 THE VALUE OF ADALIMUMAB TROUGH LEVELS AND CLINICAL ASSESSMENTS IN PREDICTING CLINICAL RESPONSE IN PATIENTS WITH ESTABLISHED RHEUMATOID ARTHRITIS AND AN INADEQUATE RESPONSE TO METHOTREXATE}

J. Smolen ${ }^{1}$, N. Mostafa ${ }^{2}$, X. Huang ${ }^{2}$, P. Noertersheuser ${ }^{3}$, B. Kluender ${ }^{3}$, K. Chen ${ }^{2}$, J. Kalabic ${ }^{3}$, I. Sainsbury ${ }^{2}$, R. Oerlemans ${ }^{4}$, S. Florentinus ${ }^{4}$, G. Burmester ${ }^{5}{ }^{1}$ Medical University of Vienna, Vienna, Austria; ${ }^{2}$ AbbVie Inc., North Chicago, USA; ${ }^{3}$ AbbVie GmbH and Co. KG, Ludwigshafen, Germany; ${ }^{4}$ AbbVie B.V., Hoofddorp,

Netherlands; ${ }^{5}$ Charité - Universitätsmedizin, Berlin, Germany

Background: Low trough levels of the tumour necrosis factor inhibitor, adalimu mab (ADL), and anti-ADL antibodies (AAA) were reported to be correlated with lack of response at later time points in patients (pts) with rheumatoid arthritis (RA). ${ }^{1}$

Objectives: To assess the ability of ADL trough levels and clinical assessments at Week 12 to predict clinical remission (REM) after 24 weeks (wks) of treatment with ADL \pm methotrexate (MTX) in established RA pts.

Methods: Data from MTX inadequate responders (MTX-IR) pts with established RA with available measurement of ADL trough levels and clinical assessments at Wks 12 and 24 from several clinical trials were pooled: for pts who received ADL +MTX combination therapy from DE009, DE019, M10-261 and M13-390; for pts who received ADL monotherapy from DE011, M10-261 and M13-390. Efficacy endpoints at Wk 24 were DAS28-CRP $<2.6$ and DAS28-CRP low disease activity $($ LDA,$<3.2)$, remission (REM) and LDA by simplified disease activity index (SDAI, $\leq 3.3$ and $\leq 11$ respectively); REM and LDA by clinical disease activity index (CDAI, $\leq 2.8$ and $\leq 10$ respectively). Each of the pooled datasets was randomly and equally split into training and testing sets. Predictive modelling was performed on the training set, and the best-performing model was selected and validated in the testing set. The performance of the final model was reported based on the testing set

Results: Based on the cutoffs selected by the predictive model, ADL concentrations at Wk 12 were only slightly predictive for Wk 24 clinical assessment in the ADL monotherapy group, but not in the ADL+MTX group (table 1). However, based on achievement of the specified CDAI, SDAI or DAS28-CRP score at Wk 12 (selected by the model), pts were correctly predicted to reach Wk 24 REM or LDA with an accuracy of $80 \%-90 \%$ and area under the receiver operating characteristic curve (AUC) of $75 \%-90 \%$ (table 2 ). As an example, pts on ADL monotherapy with DAS28 $<3.3$ at Wk 12 had $60 \%$ and $70 \%$ chance of reaching Wk 24 DAS28-CRP $<2.6$ and LDA respectively, whereas pts with DAS28 $\geq 3.3$ had $0 \%$ and $7 \%$ chance of achieving Wk 24 DAS28-CRP $<2.6$ and LDA, respectively (table 1). Pts on ADL+MTX with Wk 12 SDAl $<12.5$ had a $25 \%$ and $77 \%$ chance of achieving SDAI REM and LDA at Wk 24, respectively.

Abstract THU0185 - Table 1

\begin{tabular}{|c|c|c|c|c|c|c|c|c|c|c|}
\hline \multicolumn{11}{|c|}{ Ability of Week 12 Drug Concentration to Predikt Disease Control at Week 24 in Patients Treated with ADL /- MTX } \\
\hline $\begin{array}{l}\text { Week } 24 \\
\text { Endpoints }\end{array}$ & $\begin{array}{l}\text { Week } 12 \\
\text { conc } \\
(\mu \mathrm{g} / \mathrm{m})\end{array}$ & $\begin{array}{l}\text { High conc } \\
\text { resp rate (n) }\end{array}$ & $\begin{array}{l}\text { Low conc } \\
\text { resp rate (n) }\end{array}$ & Sensitivity & spectifictiy & & PDV & NoV & & AUC \\
\hline \multicolumn{11}{|c|}{ ADL Monotherapy } \\
\hline DAS28<2.6 & $>7.62$ & $0.36(11)$ & $0.05(42)$ & 0.67 & 0.85 & & 0.36 & 0.95 & & 0.76 \\
\hline CDAI REM & $>7.62$ & $0.27,(11)$ & $0.05(42)$ & 0.60 & 0.83 & & 0.27 & 0.95 & & 0.72 \\
\hline SOAI REM & $>7.62$ & $0.27(11)$ & $0.05(42)$ & 0.60 & 0.83 & & 0.27 & 0.95 & & 0.72 \\
\hline DAS28 LDA & $>6.53$ & $0.42(12)$ & $0.122(41)$ & 0.50 & 0.84 & & 0.42 & 0.88 & & 0.77 \\
\hline CDAI LDA & $>7.27$ & $0.46(11)$ & $0.143(42)$ & 0.46 & 0.86 & & 0.46 & 0.86 & & 0.77 \\
\hline SOAI LDA & $>6.806$ & $0.42(12)$ & $0.171(41)$ & 0.42 & 0.83 & & 0.42 & 0.83 & & 0.74 \\
\hline \multicolumn{11}{|c|}{ ADL + MTX Combination Therapy Combination Therapy } \\
\hline DAS28 $<2.6$ & $>9.03$ & $0.24(46)$ & $0.24(86)$ & 0.34 & 0.65 & & 0.24 & 0.76 & & 0.50 \\
\hline CDAI REM & $>7.43$ & $0.10(68)$ & $0.11(64)$ & 0.5 & 0.48 & & 0.10 & 0.89 & & 0.49 \\
\hline SDAI REM & $>7.02$ & $0.11(70)$ & $0.10(62)$ & 0.57 & 0.48 & & 0.11 & 0.90 & & 0.52 \\
\hline DAS28 LDA & $>8.87$ & $0.41(49)$ & $0.42(83)$ & 0.36 & 0.62 & & 0.41 & 0.58 & & 0.52 \\
\hline CDAI LDA & $>4.50$ & $0.42(100)$ & $0.44(32)$ & 0.75 & 0.24 & & 0.42 & 0.56 & & 0.46 \\
\hline SOAI LDA & $>9.00$ & $0.46(46)$ & $0.47(66)$ & 0.34 & 0.65 & & 0.46 & 0.54 & & 0.51 \\
\hline \multicolumn{11}{|c|}{ Ability of Selected Week 12 Cilinical Scores to Predict Disease Control at Week 24 in Patients Treated with ADL /- MTX } \\
\hline & & $\begin{array}{c}\text { Pts } \\
\text { meeting } \\
\text { cut-off }\end{array}$ & $\begin{array}{c}\text { Pts not } \\
\text { meeting } \\
\text { cut-off }\end{array}$ & & & & & & & \\
\hline $\begin{array}{l}\text { Week } 24 \\
\text { Endpoints }\end{array}$ & Week $12 \mathrm{C}$ & utoff & $\begin{array}{l}\begin{array}{l}\text { respp. } \\
\text { rate }\end{array} \\
\end{array}$ & $\begin{array}{l}\text { resp. } \\
\text { rate }\end{array}$ & $\begin{array}{l}\text { Senst- } \\
\text { thity }\end{array}$ & $\begin{array}{l}\text { Spect- } \\
\text { fictity }\end{array}$ & PPV & NPV & $\begin{array}{l}\text { Accel- } \\
\text { racy }\end{array}$ & AUC \\
\hline \multicolumn{11}{|c|}{ ADL Monotherapy } \\
\hline DAS28<2.6 & DAS28 CS & 10 & 0.60 & $43 \quad 0.0$ & 1.00 & & 0.60 & 1.00 & 0.93 & 0.96 \\
\hline CDAI RE & CDAl<9 & 8 & 0.63 & 0.0 & & & & 1.00 & 0.94 & 0.97 \\
\hline 528 LDA & DAS28 & 10 & $\begin{array}{l}0.50 \\
0.70\end{array}$ & $\begin{array}{l}0.0 \\
0.07\end{array}$ & $\begin{array}{l}1.70 \\
0.70\end{array}$ & 0.93 & $\begin{array}{l}0.50 \\
0.70\end{array}$ & $\begin{array}{l}1.90 \\
0.93\end{array}$ & $\begin{array}{l}0.81 \\
0.89\end{array}$ & $\begin{array}{l}0.95 \\
0.82\end{array}$ \\
\hline CDAI LDA & CDAI 11 & 10 & 0.70 & 0.09 & 0.64 & & 0.70 & 0.91 & 0.87 & 0.78 \\
\hline SOAI LDA & SOAI $<12$ & 10 & 0.80 & $\begin{array}{ll}43 \quad 0.09 \\
\end{array}$ & 0.67 & 0.95 & 0.80 & 0.91 & 0.89 & 0.81 \\
\hline \multicolumn{11}{|c|}{$\mathrm{ADL}+\mathrm{MTX}$ Combination Therapy } \\
\hline DAS28<2.6 & DAS28 <3 3 & 37 & 0.49 & 0.15 & 0.56 & & & 0.85 & 75 & 0.69 \\
\hline & & 29 & & 103 & & & & & & 0.86 \\
\hline & & $\begin{array}{l}32 \\
61\end{array}$ & & $\begin{array}{l}100 \\
71\end{array}$ & & & & & & 0.84 \\
\hline $\begin{array}{l}\text { DAS28 LDA } \\
\text { CDAI LOA }\end{array}$ & CDAI 12 & 57 & 0.74 & $\begin{array}{l}0.16 \\
0.19\end{array}-19$ & 0.0 .75 & 10 & & 0.81 & 88 & 0.78 \\
\hline SOAI LDA & SOAI $<12$ & 57 & 0.77 & 0.23 & 0.72 & 0.82 & 0.77 & 0.77 & 0.77 & 0.77 \\
\hline
\end{tabular}

Conclusions: The ADL concentrations at Week 12 selected by the prediction model were weak predictors of disease control at 6 months, especially for pts on ADL+MTX combination therapy. However, using the model-selected cutoffs of composite clinical endpoints at Wk 12, disease control after 6 months of ADL \pm MTX treatment could be correctly predicted in $70 \%-80 \%$ of pts.

\section{REFERENCES:}

[1] Jani, et al. Arthritis \& Rheumatol 2015

[2] Huang X, et al. Statistics in Medicine 2017.

Acknowledgements: AbbVie Inc was the study sponsor, contributed to study design, data collection, analysis and interpretation, and to writing, reviewing, and approval of final version. Medical writing support was provided by Naina Barretto, PhD, of AbbVie, Inc.

Disclosure of Interest: J. Smolen Grant/research support from: AbbVie Inc, Consultant for: AbbVie Inc, N. Mostafa Shareholder of: AbbVie Inc, Employee of: AbbVie Inc, X. Huang Shareholder of: AbbVie Inc, Employee of: AbbVie Inc, P. Noertersheuser Shareholder of: AbbVie Inc, Employee of: AbbVie Inc, B. Kluender Shareholder of: AbbVie Inc, Employee of: AbbVie Inc, K. Chen Shareholder of: AbbVie Inc, Employee of: AbbVie Inc, J. Kalabic Shareholder of: AbbVie Inc, Employee of: AbbVie Inc, I. Sainsbury Shareholder of: AbbVie Inc, Employee of: AbbVie Inc, R. Oerlemans Shareholder of: AbbVie Inc, Employee of: AbbVie Inc, S. Florentinus Shareholder of: AbbVie Inc, Employee of: AbbVie Inc, G. Burmester Grant/research support from: AbbVie Inc., Bristol-Myers Squibb, Merck, Roche, Pfizer, and UCB, Consultant for: AbbVie Inc., Bristol-Myers Squibb, Merck, Roche, Pfizer, and UCB, Speakers bureau: AbbVie Inc., BristolMyers Squibb, Merck, Roche, Pfizer, and UCB DOI: 10.1136/annrheumdis-2018-eular.2721 